\title{
NOTAS SOBRE ALGUNS DOCUMENTOS INEXPLORADOS PARA A HISTÓRIA DE ANGOLA: OS RÓIS DOS CONFESSADOS DE 1704
}

\author{
Notes on Some Unexplored Documents for the History of Angola: \\ The Rolls of the Confessed in 1704
}

José C. Curto ${ }^{1}$

\section{RESUMO}

Este trabalho baseia-se numa fonte quantitativa que tem sido utilizada por historiadoras(es) nas últimas décadas, os róis ou arrolamentos de confessados. No caso particular de Angola, esta documentação contém informações demográficas dos indivíduos e da(s) família(s) que habitavam os fogos pertencentes às freguesias do Bispado de Angola, no ano de 1704. Tendo como finalidade listar os fregueses que haviam cumprido seus deveres religiosos, o rol de confessados de 1704 não só permite melhor compreender as estruturas de populações que antecederam o desenvolvimento de recenseamentos, no final do século XVIII, mas, também, possibilita investigar os padrões de família, de habitação, de riqueza ou pobreza dos moradores e soldados e, especialmente, o número de escravos que esses indivíduos possuíam. Esta contribuição descreve essas possibilidades, com foco no presídio de Muxima.

Palavras-chave: Angola. História. Muxima. Rois de Confessados. Século XVIII.

\begin{abstract}
This work is based on a quantitative source that has been used by historians in recent decades to help better uncover the past - lists of the confessed. In the particular case of Angola, this documentation contains demographic information on the individuals, as well as families, that lived in particular parishes of the Bishopric of Angola during 1704. In order to ascertain the believers who had fulfilled their religious duties, the 1704 lists of the confessed in Angola not only allow us to better understand the population structures that preceded the development of censuses in the late 18th century, but also to investigate patterns relating to family, housing, wealth or poverty of residents and soldiers and, especially, the number of slaves that both individuals and families owned. This contribution describes these possibilities, with a focus on the presídio or military administrative area of Muxima.
\end{abstract}

Keywords: Angola. History. Muxima. Lists of the Confessed. XVIII century.

\footnotetext{
${ }^{1}$ Professor Catedrático, Departamento de História, York University, Toronto, Canadá. E-mail: jccurto@yorku.ca REVISTARELEGENSTHRÉSKEIA - 2020 - UFPR
} 
Nas últimas décadas, os róis ou arrolamentos de confessados, entre outras inúmeras fontes, tem se tornado um importante documento utilizado por historiadores para reconstruir e melhor compreender as estruturas e padrões migratórios de populações que antecederam o desenvolvimento dos recenseamentos modernos. Como os registros de batismos, de casamentos e de óbitos, os róis de confessados eram listas nominativas que passaram a ser exigidas pelas autoridades eclesiásticas (provisores e vigários gerais) após o Concílio de Trento, em meados do século XVI. Com a instituição desta reforma pela Igreja Católica, cada pároco de freguesia deveria produzir este documento. Em cada ano, em período anterior a quaresma, cada pároco tinha a obrigação de arrolar os fregueses que haviam cumprido seus deveres religiosos, ou seja, os indivíduos que haviam se confessado e comungado. Tal arrolamento, realizado pelas ruas ou lugares da freguesia, listava os indivíduos e a(s) família(s) que habitavam em cada fogo. Os fregueses não podiam escapar do arrolamento anual, pois corriam o risco de serem excomungados. O único grupo da população que, normalmente, não se encontrava listado neste documento é o dos menores de sete anos, tanto femininos como masculinos: isto porque, nesta idade, ainda não tinham feito sua primeira comunhão. Posto isto, o rol dos confessados constituiu o protótipo do recenseamento moderno para as populações católicas.

No mundo lusófono, os róis de confessados constituem uma fonte histórica incontornável para o período anterior aos meados do século XIX. No caso de Portugal, onde este documento eclesiástico parece predominar, os arrolamentos de confessados têm sido utilizados para reconstruir as estruturas e movimentos de populações históricas, especialmente a nível micro, isto é, em termos da freguesia (Ver, entre outros: Amorim; Barros; Borges 2000 e 2009; Capela; Comissoli; Pereira; Ribeiro; Rijo; Rodrigues, T.; Rodrigues \& Neto; Sequeira). No Brasil, para o período anterior a sua independência, em 1822, os róis de confessados têm levado historiadores a desenvolver importantes percepções sobre sociedades escravagistas, também no âmbito da freguesia (Ver, por exemplo: Antunes; Libby e Paiva 2000a, 2000b; Libby 2009, 2013, 2016; Malaquias 2010, 2013, 2014, 2017). Em relação à Ilha de Moçambique e aos prazos no Tete, os róis de confessados têm sido não menos significantes: entre 1722 e o final da década 1820, em particular, este tipo de documento foi utilizado na elaboração local de listas populacionais que, por sua vez, tem ajudado

REVISTARELEGENS THRÉSKEIA - 2020 - UFPR 
vários historiadores a reconstruir as estruturas e os movimentos da população colonial e colonizada, incluindo a escravizada (Rodrigues, E; Silva, F. 2015, 2017; Wagner 2001, 2010).

Todavia, a existência do arrolamento de confessados é bastante variável conforme a freguesia. Por exemplo, na freguesia mineira de S. Antônio da Vila de S. José, um único arrolamento de confessados, referente a 1795, tem sido localizado para todo o século XVIII. Entretanto, no caso de Rio Grande de São Pedro (Rio Grande do Sul), na segunda metade do século XVIII, existem vários róis de confessados para as freguesias de Viamão e de Porto Alegre (Ver, entre outros: Blanco; Danilevicz; Freitas; Gomes, 2012, 2014, 2018; Schantz; Scott; Sirtori). Para algumas freguesias em Angola, há também alguns destes documentos. Mas, como veremos a seguir, estes se referem a um só ano no início dos setecentos.

No primeiro volume de um catálogo, publicado em 1850, dos manuscritos então existentes na Biblioteca Pública Eborense - instituição que depois da expulsão dos Jesuítas do império português, nos meados do século XVIII, recolheu grande parte da biblioteca e fontes que alimentavam a sua universidade na cidade de Évora -, pode-se ler a seguinte referência: "Noticias das Igrejas do Bispado de Angola, e Relacão da gente que tem em cada Freguezia”: ademais, logo abaixo desta referência há ainda a informação adicional de que "São Relações pedidas aos Parochos pelo Bispo D. Luis Simões Brandão em 1704" (Rivara). Essa fonte ainda faz parte da documentação reservada da Biblioteca Pública Eborense, hoje denominada Biblioteca Pública de Évora, com a cota Códice CXVI, 2-15, n $16 .^{2}$ Aqui temos os únicos arrolamentos de confessados conhecidos para Angola. ${ }^{3}$

Como surgiu essa fonte, única, ainda inexplorada ${ }^{4}$ e, portanto, de grande importância para a História de Angola? Dom Luis Simões Brandão foi nomeado, no princípio de 1702, para governar o Bispado de Angola e Congo (Zau; Gabriel 1980). Sete meses depois, talvez ainda em Portugal, mandou publicar uma pastoral com várias instruções para seus párocos na colônia. Uma delas

\footnotetext{
${ }^{2}$ Biblioteca Pública de Évora (BPÉ), Códice CXVI, 2-15, n 16, “Noticias das Igrejas do Bispado de Angola, e Relação da gente que tem em cada Freguezia" [1704].

${ }^{3} \mathrm{O}$ Arquivo do Bispado de Luanda, repositório central da documentação eclesiástica produzida em Angola, não possui nenhuma destas fontes anterior ao final do século XIX. Ver, em particular: Birmingham; Curto 2002, Candido; Jadin; Miller; Pacheco 1990, 1992.

${ }^{4}$ Este documento se encontra referenciado, mas seus dados demográficos não são utilizados, em: Reginaldo 2011, 2016; Thornton 2020.
}

REVISTARELEGENS THRÉSKEIA - 2020 - UFPR 
exigia de cada pároco "antes da Quaresma...correr toda a sua freguezia, e fazer dous Roes distinctos, e Separados: Hum em que aparesa todos os brancos mayores e menores; e outro em que aparesa os pretos assim forros como escravos...". Demais, os fregueses deveriam ser alistados por "seos nomes, acrecentando o sitio aonde morão" . Foram estas as instruções que resultaram nas relações da gente "pertencente e assistente" em cada freguesia, os róis de confessados, primeiro identificados no catálogo de 1850 dos manuscritos existentes na então Biblioteca Pública Eborense.

Os arrolamentos requisitados pelo Bispo Brandão ${ }^{6}$, que sobreviveram à ação do tempo e ainda se encontram na Biblioteca Pública de Évora, constam na Tabela 1 deste artigo. À primeira vista, temos dezoito róis de confessados; todavia, o número é efetivamente mais reduzido. Após uma leitura mais pormenorizada, notamos que o "Rol dos Moradores de Mochima", encontrado entre as folhas 104-104v e 109-114v ${ }^{7}$, continua entre as folhas 115-121v. Estas últimas folhas contêm: arrolamentos de escravos pertencentes a residentes de Muxima já falecidos (Anna Antunes e Dona Sezilia Tavares) e escravos em Muxima pertencentes a indivíduos de outras freguesias (Bertholomeu Gonçalvez e Tomas da Silva). E, não menos importante, esta segunda parte do rol de Muxima possui também listas de "filhos" ou sujeitos forros de quatro dos sobas locais, vassalos da coroa portuguesa: Soba D. Giorge, ucusu vagonge; Soba D. Diogo, qui a gonga; Soba D. Antonio, quizau tembo; e Soba D. Francisco Caculo Cahongo. Portanto, restam somente quatro arrolamentos relativos a outros espaços geo-administrativos: as freguesias associadas aos distritos de Dande (fls. 105-107) ${ }^{8}$ e do Icolo (fls. 133-137) e aquelas situadas nos presídios das Pedras [de Pungo Andongo] (fls. 138-140v) e de Ambaca (fls. 160v-165v e 167-168). Infelizmente, os róis

\footnotetext{
${ }^{5}$ BPÉ, Códice CXVI, 2-15, n. 15, Pastoral do Bispo Dom Luís Simões Brandão, 26 de setembro de 1702, fls. 63v-64.

${ }^{6}$ Este Bispo vai ter um papel importante na produção de arrolamentos de confessados em outros lugares. Depois do Arcebispo Dom Sebastião Monteiro da Vide convocar, para meados de 1704, o $1^{\circ}$ Concílio Da Província Eclesiástica da Bahia, com quatro Dioceses Sufragâneas constituintes (Rio de Janeiro, Olinda, S. Tomé e Angola), Dom Luís Simões Brandão marcou presença. Como se sabe, foi durante esse concílio - e o sínodo que ocorreu logo a seguir -, que foram escritas, sob a coordenação de Dom Sebastião, as Constituições Primeiras do Arcebispado da Bahia, documento que, uma vez impresso em 1707, padronizou procedimentos eclesiásticos, incluindo os róis de confessados, tanto no Brasil como em São Tomé e em Angola. Ver: Beozzo; Campos \& Merlo. Demais, foi o mesmo Dom Luís Simões Brandão que, no início de maio de 1732, então vigário capitular da Diocese de Coimbra, deu ordem para se realizar um inquérito paroquial específico com vista a produzir informação populacional. Ver: Rodrigues \& Neto, p. 52. No entanto, não devemos esquecer que este Bispo tambem foi acusado pelo Rei de Portugal de se envolver no comércio dos escravos: ver SILVA, C (2007).

${ }^{7}$ Nenhuma razão nos é dada para explicar o porque desta interrupção na numeração das folhas.

${ }^{8}$ De modo semelhante, nenhuma razão nos é dada para explicar a inserção desta informação entre os dados referentes à Muxima.
} 
dos sobas, entre as folhas 151 e 155, quer dizer, as autoridades africanas da lotação da vila de Massangano, dos Dembos, do Quanza, de Muxima e do Icolo não oferecem informações sobre seus sujeitos.

Faltam, portanto, a maior parte das freguesias. No eixo do rio Quanza, por exemplo, não possuímos róis de confessados para as freguesias associadas com os presídios de Massangano e de Cambambe, assim como o distrito de Calumbo. As duas freguesias de Luanda, Nossa Senhora da Conceição e Nossa Senhora dos Remédios, também estão em falta. Mais para o sul, não possuímos o arrolamento da população da freguesia de Nossa Senhora do Pópulo em Benguela nem o daquela associada ao presídio de Caconda. Estas lacunas podem ter sido o resultado de várias circunstâncias. Certamente que as instruções do Bispo Brandão não foram seguidas em todas as freguesias: nem sempre havia pároco para tratar das necessidades espirituais dos fregueses; ao mesmo tempo, os párocos eram frequentemente negligentes em seus deveres, especialmente quando se encontravam em freguesias distantes de centros administrativos como Luanda (Mello; Gabriel 1978). Além disso, boa parte da documentação produzida em Angola tem se perdido - ou porque os documentos foram extraviados ou foram destruídos pela formiga salalé (Pacheco 2000; Thompson). E, finalmente, seria insensato presumir que todos os róis de confessados produzidos em Angola, durante 1704, chegaram às mãos dos Jesuítas em Évora.

Todavia, a existência destes arrolamentos para certas freguesias de Angola, no princípio dos setecentos, oferece perspectivas importantes sobre suas populações católicas. Vejamos, por exemplo, o que nos pode dizer o rol de confessados da freguesia de Muxima. Esta, situada a cerca de 130 quilômetros ao sudeste de Luanda, é umas das mais antigas freguesias de Angola-colônia. Foi criada após a fundação da pequena vila de Muxima, no fim do século XVI, para encabeçar o presídio do mesmo nome, na margem sul do rio Quanza, que pretendia controlar o fluxo comercial com o povo da Kisama. Em 1704, foram aqui arroladas perto de 2,200 pessoas. Parte desta gente morava na vila em volta de duas instituições: a pequena capela da Nossa Senhora da Conceição e da pequena fortaleza construída a mando da administração colonial Portuguesa. Outra parte vivia nos arredores da vila, onde os principais residentes tinham seus arimos ou propriedades agrícolas cultivadas por escravos e dependentes. Finalmente, uma proporção significativa possuía suas residências dentro do espaço alocado ao presídio, sob o controle imediato de autoridades políticas africanas avassaladas a Coroa de Portugal. Assim, qual teria sido o peso demográfico das pessoas

REVISTARELEGENS THRÉSKEIA - 2020 - UFPR 
católicas arroladas em 1704 dentro da população total do presídio? Com os dados disponíveis, esta é uma pergunta impossível de ser respondida. Todavia, sabemos que Muxima foi o menor dos presídios no eixo do corredor do rio Quanza: no início de 1796, por exemplo, contava somente com 9,546 habitantes (Curto 2018). Talvez não seja errôneo sugerir que os cerca de 2,200 indivíduos listados no arrolamento dos confessados de 1704 constituíam algo entre um quarto e metade da população total de Muxima.

De qualquer maneira, o rol de confessados de 1704 da freguesia de Muxima oferece importantes informações, não só sobre a população católica então listada, mas, também, sobre os indivíduos que ficaram fora do arrolamento. Vejamos, por exemplo, a Tabela 2. O padre responsável por este alistamento dividiu a população em várias categorias. Primeiro temos a população civil, genericamente referida como moradores, assim como seus escravos e outros dependentes, destacada da população africana controlada por várias autoridades políticas indígenas. Os moradores civis estão classificados entre casados, com sua descendência, solteiros/as, e viúvas. Depois temos a população militar, essencial em qualquer presídio para sua defesa, também classificada entre casados, com sua descendência e familiares de suas esposas, e os solteiros. Uma terceira categoria populacional é constituída por meninos. Forros/as (ou livres e sem agregação) representam uma quarta classificação, seguidos de um grupo de gente dita da Igreja. Forros/as (ou livres) agregados a moradores e/ou soldados compõem a sexta categoria demográfica. Segue depois a penúltima categoria populacional: gente escravizada por morador e/ou soldado. Por fim, temos os filhos forros ou os sujeitos livres de sobas, e outras entidades africanas, avassalados a coroa portuguesa.

Assim sendo, as classificações dos róis de confessados de 1704 da freguesia de Muxima possibilitam uma série de análises demográficas. Por esta população estar listada nominalmente, temos um arrolamento em que todas as classificações populacionais podem ser analizadas em termos de gênero. Demais, salvo o caso de sujeitos livres de sobas e outras entidades africanas avassaladas, podemos investigar tanto padrões de família, como de habitação, para o resto (neste caso a maioria) da população. A riqueza (ou pobreza) dos moradores e soldados pode ser determinada através do número de agregados e, especialmente, de escravos que cada um possuía. A posse de escravos é, efetivamente, uma das importantes questões sobre o qual este tipo de documento oferece bastante informação.

REVISTARELEGENS THRÉSKEIA - 2020 - UFPR 
Por seu torno, a população aparentemente não arrolada também pode trazer esclarecimentos interessantes sobre certos aspetos desta sociedade. Por exemplo, porque será que dentro da categoria de moradores, temos viúvas, mas nenhum viúvo? Será este um indicador de uma comunidade de freguezes composta predominantemente pelo sexo feminino? Por outro lado, qual a razão para a existência de uma categoria exclusiva para meninos, mas não para meninas? Estavam as meninas alistadas nas unidades familiares de seus pais ou, talvez, até já casadas, e assim fazendo desde tenra idade parte dos fogos de seus maridos? E, não menos importante, a população controlada pelos quatro sobas avassalados é composta somente por sujeitos livres. Aonde se encontravam os escravos, sejam eles de linhagem ou para venda no mercado Atlântico? Será que para estes, devido seu número certamente elevado, não era prático nem econômico fazer com que fossem inseridos no mundo dos católicos? Ou será que este lapso constituía uma maneira para os sobas se representarem como pobres e, assim, melhor escapar aos tributos impostos a vassalos (Heywood \& Thornton)?

Finalmente, temos a questão da cor (ou pertença racial). No título do rol de confessados que estamos descrevendo, seu autor escreveu explicitamente que a dita listagem era "dos Moradores, Soldados e mais gente branca Pertences e assistentes neste prezidio e Igreja de Nossa Senhora da Conceição e Parochia de Mochima"9 . Mas tal era uma impossibilidade visto que, no contexto de um presídio do interior, independente do gênero, raro eram os moradores e os soldados de cor branca (Carvalho; Carvalho \& Ferreira; Corrêa; Couto; Curto 2018; Guedes; Queiroz; Venâncio). Ao mesmo tempo, gente de cor preta não poderia só ser livre ou escrava. No princípio do século XVIII, o intercâmbio entre o mundo dos africanos e o mundo dos português-brasílicos já há muito que tinha produzido outro estatuto legal: o preto alforriado. E o que dizer do pardo ou mulato? Estavam eles "escondidos" dentro da população arrolada como branca?

Em suma, embora não incluindo toda a população e nem sempre arrolando os fregueses por meio de classificações precisas, a lista de confessados de Muxima para 1704 possui informações preciosas para reconstruir vários aspectos desta comunidade ${ }^{10}$. $\mathrm{O}$ mesmo se pode dizer para os arrolamentes dos distritos do Dande e de Icolo, assim como os presídios de Ambaca e de Pedras de Pungo Andongo. A importância destas fontes se torna ainda mais significativa quando lembramos

\footnotetext{
${ }^{9}$ Ênfase dada pelo autor deste texto.

${ }^{10}$ É precisamente esta a tarefa em um trabalho que presentemente tenho em andamento.
} 
que os primeiros censos em Angola-colônia foram realizados apenas em 1777-1778 (Thornton 1980; Curto 1994; Curto \& Gervais; Silva, D.).

\begin{tabular}{|c|c|}
\hline \multicolumn{2}{|c|}{$\begin{array}{l}\text { Tabela 1. Biblioteca Publica de Évora, Códice CXVI, 2-15, n¹6: } \\
\text { "Relacão da gente que tem em cada Freguezia [1704, Angola]" }\end{array}$} \\
\hline Fls. 104-104v \& 109-114v & Rol dos Moradores de Mochima \\
\hline Fls $105-107$ & Rol dos Moradores do Dande \\
\hline Fls. $115-115 v$ & $\begin{array}{l}\text { Rol dos escravos da defunta Anna Antunes aggredados ao Convento de } \\
\text { S. Jozeph em esta cidade de Luanda }\end{array}$ \\
\hline Fl. 116 & $\begin{array}{l}\text { Rol dos escravos de Bertholomeu Glz Encapeladoz na Capella da Sra. } \\
\text { Da Conceiçam de Mochima }\end{array}$ \\
\hline Fl. 117 , coluna 1 & Rol dos escravos de Tomas da Silva em Massangano \\
\hline Fl. 117 , coluna 2 & Rol dos escravos de Dona Sezilia Tavarez \\
\hline Fls. 118-118v & Rol dos Forroz filhos do Sova D. Giorge ucusu vagonge \\
\hline Fls. 119-119v & Rol dos Forroz filhos do Sova D. Diogo qui a gonga \\
\hline Fls. $119 \mathrm{v}-120$ & Rol dos Forroz filhos do Sova D. Antonio quizau tembo \\
\hline Fls. 120v & Forroz de Caculo \\
\hline Fls. 121-121v & Rol dos Forroz filhos do Sova D. Francisco Caculo Cahongo \\
\hline Fls. 133-137 & Rol dos Moradores do Icollo \\
\hline Fls. 138-140v & Rol dos Moradores do Prezidio das Pedras [de Pungo Andongo] \\
\hline Fls. $151-151 \mathrm{v}$ & Rol dos Sovas da Lotasam desta Villa [Massangano] \\
\hline Fls. 153-153v & Rol dos Dembos \\
\hline Fl. 155 & Sovas do Quanza, Sovas de Muxima, e Sobas do Icollo \\
\hline Fls. $160 \mathrm{v}-165 \mathrm{v}$ & Rol dos Moradores de Ambaca \\
\hline Fls. 167-168 & Rol dos Sovas de Ambaca \\
\hline
\end{tabular}




\section{Tabela 2:}

"Rol dos Moradores, Soldados e mais gente branca Pertences e assistentes neste prezidio e Igreja de N.a S.ra da Conceiçam e Parochia de Mochima"

Categorias da População em 1704

1a. Moradores casados e seus filhos/suas filhas

1b. Moradores solteiros

1c. Viúvas

2a. Soldados casados, seus filhos/suas filhas e familiares de suas esposas

2b. Soldados solteiros

3. Meninos

4. Forros/as (pretos/as livres, sem agregação)

5 Gente da Igreja

6. Forros/as (pretos/as livres) agregados a moradores e soldados

7. Escravos/as de moradores e soldados

8. Forros/as (pretos livres) debaixo de sobas e outras entidades africanas

Fonte: ver Tabela 1. 


\section{REFERÊNCIAS BIBLIOGRÁFIA}

AMORIM, M. N. B. Exploração dos róis de confessados duma paróquia de Guimarães (1734-1760). Guimarães: Centro Gráfico, 1983.

ANTUNES, W. O. Escravidão e Sociedade na América Portuguesa: a freguesia de São José do Rio das Mortes, 1750-1800. Minas Gerais no século XVIII. História: revista da FLUP, v. 1, IV série, p.133-154, 2011.

BARROS, M. S. C. F. M. São José, Bairro Tridentino. 2017. Tese (Doutorado em Estudos Urbanos) - Faculdade de Ciências Sociais e Humanas, Universidade Nova de Lisboa, Lisboa.

BEOZZO, J. O. Bahia, Provincial Council, Religion Past and Present. Disponível em:

$<$ https://referenceworks.brillonline.com/entries/religion-past-and-present/*-SIM_01418>. Acesso em: 23 ago. 2020.

BIRMINGHAM, D. Themes and Resources of Angolan History. African Affairs, v. 73, p. 188203, 1974.

BLANCO, M. M. Pelas veredas da senzala: família escrava e sociabilidades no mundo agrário (Campos de Viamão, c.1740- c.1760). 2012. Dissertação (Mestrado em História) - Instituto de Filosofia e Ciências Humanas, Universidade Federal do Rio Grande do Sul, Porto Alegre.

BORGES, M. J. Migration Systems in Southern Portugal: Regional and Transatlantic Circuits of in the Algarve (Eighteenth-Twentieth Centuries). International Review of Social History, Cambridge, v. 45, p. 171-208, 2000.

BORGES, M. J. Chains of Gold: Portuguese Migration to Argentina in Transatlantic Perspective. Leiden: Brill, 2009.

CAMPOS, A. P.. MERLO, P. M. S. Sob as bênçãos da Igreja: o casamento de escravos na legislação brasileira. Topoi, Rio de Janeiro, v. 6, p. 327-361, 2005.

CANDIDO, M. P. Engendering West Central African History: The Role of Urban Women in Benguela in the Nineteenth Century. History in Africa, v. 42, p. 7-36, 2015.

CAPELA, V. As Freguesias do Distrito de Viana do Castelo nas Memórias Paroquiais de 1758. Braga: Casa Museu de Monção/Universidade do Minho, 2005.

CARVALHO, A.; FERREIRA, R. G. Piedade, sobas e homens de cores honestas nas Notícias do Presídio de Massangano, 1797. In: SCOTT, A. S. V. et al. (Orgs.). Mobilidade social e formação de hierarquias: subsídios para a história da população. 1a ed. São Leopoldo: Oikos/Editora Unisinos, 2014, p. 129-171. 
CARVALHO, F. M. Os homens do rei em Angola: sobas, governadores e capitães mores, séculos XVII e XVIII. 2013. Tese (Doutorado em História) - Instituto de Ciências Humanas e Filosofia, Universidade Federal Fluminense, Rio de Janeiro.

COMISSOLI, Adriano. Do Arquipélago ao Continente: estratégias de sobrevivência e ascensão social na inserção açoriana nos Campos de Viamão (séc. XVIII). Revista Aedos, Porto Alegre, v. 2, p. 74-96, 2009.

CORRÊA, C. P. Cambambe, Angola, no Contexto do Comércio Atlântico de Escravizados (1790-1850). 2019. Tese (Doutorado em História Social) - Universidade Federal do Rio de Janeiro, Rio de Janeiro.

COUTO, Carlos. Os capitães-mores em Angola no século XVIII: Subsídio para o estudo da sua actuação. Luanda: Instituto de Investigação Científica de Angola, 1972.

CURTO, J. C. Sources for the Pre-1900 Population History of Sub-Saharan Africa: the case of Angola, 1773-1845. Annales de Demographie Historique, Paris, p. 319-338, 1994.

CURTO, J. C. As If From a Free Womb’: Baptismal Manumissions in the Conceição Parish, Luanda, 1778-1807. Portuguese Studies Review, v. 10, n. 1, p. 26-57, 2002.

CURTO, J. C. The Population of the Lower Kwanza River Valley, 1792-1796. Ponta de Lança: Revista Eletrônica de História, Memória \& Cultura, São Cristóvão, v. 12, n. 23, p. 95-117, 2018.

CURTO, J. C.; GERVAIS, R. R. The Population History of Luanda During the Late Atlantic Slave Trade, 1781-1844. African Economic History, v. 29, p. 1-59, 2001.

DANILEVICZ, I. M. Aspectos demográficos e padrão de posse de escravos em Viamão (1776 - 1784). 2009. Monografia (Graduação em História) - Departamento de História, Universidade Federal do Rio Grande do Sul, Porto Alegre.

FREITAS, D. T. L. Para além do matrimônio: formas de união, relações familiares e sociais na Freguesia Madre de Deus de Porto Alegre (1772-1822). 2017. Tese (Doutorado em História) - Instituto de Filosofia e Ciências Humanas, Universidade Federal do Rio Grande do Sul, Porto Alegre.

GABRIEL, M. N. Angola, cinco séculos de cristianismo. Queluz: Literal, 1978.

GABRIEL, M. N. D. Moisés Alves de Pinho e os bispos de Congo e Angola. Braga: Livraria Editora Pax, 1980.

GOMES, L. C. Uma cidade negra: escravidão, estrutura econômico-demográfica e diferenciação social na formação de Porto Alegre, 1772-1802. 2012. Dissertação (Mestrado em História) - Instituto de Filosofia e Ciências Humanas, Universidade Federal do Rio Grande do Sul, Porto Alegre.

REVISTARELEGENS THRÉSKEIA - 2020 - UFPR 
GOMES, L. C. Escravidão e agricultura no Rio Grande de São Pedro, período colonial: sugestão de um modelo de interpretação. Revista Latino-Americana de História - UNISINOS, São Leopoldo, v. 3, n. 10, p. 80-110, 2014.

GOMES, L. C. Camponeses e pequenos escravistas: estrutura econômica, reprodução social e vínculos extradomiciliares de produtores rurais em Porto Alegre e Viamão, décadas finais do século XVIII. 2018. Tese (Doutorado em História) - Instituto de Filosofia e Ciências Humanas, Universidade Federal do Rio Grande do Sul, Porto Alegre.

GUEDES, R. Exóticas denominações: manipulações e dissimulações de qualidades de cor no reino de Angola (segunda metade do século XVIII). In: ALMEIDA, S. C. C. et al, (Orgs.). Cultura e sociabilidades no mundo atlântico. 1 ed. Recife: Editora Universitária, 2012, p. 369398.

HEYWOOD, L. M.; THORNTON, J. K. African Fiscal Systems as Sources for Demographic History: The Case of Central Angola, 1799-1920. Journal of African History, v. 29, n. 2, p. 213-228, 1988.

JADIN, L. Rapport sur les recherches aux Archives d'Angola du 4 juillet au 7 septembre 1952. Bulletin de l’Institut Royal Colonial Belge, v. 24, p. 157-169, 1953.

LIBBY, D. C. Notarized and Baptismal Manumissions in the Parish of São José do Rio das Mortes, Minas Gerais (c. 1750-1850). The Americas, Washington, v. 66, n. 2, p. 211-240, 2009.

LIBBY, D. C. A Culture of Colors: Representational Identities and Afro-Brazilians in Eighteenthand Nineteenth-Century Minas Gerais. Luso-Brazilian Review, v. 50, p. 26-53, 2013.

LIBBY, D. C. Family, Stability, and Respectability: Seven Generations of Africans and Afrodescendants in Eighteenth- and Nineteenth-Century Minas Gerais. The Americas, v. 73, p. 371390, 2016.

LIBBY, D. C.; PAIVA, C. A. Alforrias e forros em uma freguesia mineira: São José d'el Rey em 1795. Revista Brasileira de Estudos de População, Belo Horizonte, v. 17, n. 1/2, jan./dez., p. 17-46, 2000.

LIBBY, D. C.; PAIVA, C. A. Manumission Practices in a Late Eighteenth-Century Brazilian Slave Parish: São José d'El Rey in 1795. Slavery and Abolition v. 21, p. 96-127, 2000.

MALAQUIAS, C. O. Trabalho, família e escravidão: pequenos produtores de São José do Rio das Mortes, de fins do século XVIII a meados do XIX. 2010. Dissertação (Mestrado em História) - Faculdade de Filosofia e Ciências Humanas, Universidade Federal de Minas Gerais, Belo Horizonte. 
MALAQUIAS, C. O. Além da Família: o Perfil Demo-Econômico dos Domicílios da Freguesia de São José do Rio das Mortes em 1795, In: Anais do XXVII Simpósio Nacional de História, n. 27, 2013, Natal: Anpuh Brasil, 22 a 26 de julho, p. 1-15.

MALAQUIAS, C. O. Remediados senhores: pequenos escravistas na freguesia de São José do Rio das Mortes, c.1790 c.1844. 2014. Tese (Doutorado em História) - Faculdade de Filosofia e Ciências Humanas, Universidade Federal de Minas Gerais.

MALAQUIAS, C. O. A família negra em liberdade: domicílios dos libertos em Minas Gerais no final do século XVIII. Acervo - Revista do Arquivo Nacional, Rio de Janeiro, n. 1, v. 30, p. 68-86, 2017.

MELLO, M. A. Angola no Fim do Século XVIII: Documentos. Boletim da Sociedade de Geografia de Lisboa, Lisboa, v. 6, pp. 274-304, 1886.

MILLER, J. C. The Archives of Luanda, Angola. International Journal of African Historical Studies, v. 7, p. 551-590, 1974.

PACHECO, C. José da Silva Maia Ferreira: Novas achegas para a sua biografia. Luanda: União dos Escritores Angolanos, 1992.

PACHECO, C. José da Silva Maia Ferreira: o homen e a sua época. Luanda: União dos Escritores Angolanos, 1990.

PACHECO, Carlos. Repensar Angola. Lisboa: Vega, 2000.

PEREIRA, I. R. Os róis dos confessados como fonte histórica. Anais da Academia Portuguesa de História, Lisboa, v. 31, 2 série, p. 271-288, 1986.

QUEIROZ, K. C. M. Poder e hierarquias sociais no presídio de Muxima (Reino de Angola, fins do século XVIII e início do XIX). 2018. Dissertação (Mestrado de História), Departamento de História e Economia, Instituto Multidisciplinar, Universidade Federal Rural do Rio de Janeiro, Rio de Janeiro.

REGINALDO, L. Os rosários dos angolas: irmandades de africanos e crioulos na Bahia setecentista. São Paulo: Alameda, 2011.

REGINALDO, L. Rosários dos pretos, São Benedito de Quissama: irmandades e devoções negras no mundo atlântico (Portugal e Angola, século XVIII). Studia Historica. Historia Moderna, Salamanca, v. 38, n. 1, p. 123-151, 2016.

RIBEIRO, A. R. A. M. C. A importância dos róis de confessados na demografia histórica: os róis de confessados da freguesia de Nossa senhora da Encarnação da Ameixoeira entre 1750 e 1760. 1989. Dissertação (Mestrado em Demografia Histórica e Social) - Faculdade de Ciências Sociais e Humanas, Universidade Nova de Lisboa, Lisboa. 
RIJO, D. M. M. A representação da freguesia de Santa Justa (Lisboa) nos róis de confessados (1693-1702). 2011. Dissertação (Mestrado em História Moderna e dos Descobrimentos) - Faculdade de Ciências Sociais, Universidade Nova de Lisboa, Lisboa.

RIVARA, J. H. C. Catalogo dos Manuscriptos da Bibliotheca Publica Eborense. v. 1. Lisboa: Imprensa Nacional, 1850.

RODRIGUES, E. Portugueses e Africanos nos Rios Sena: os Prazos da coroa em Moçambique nos Séculos XVII e XVIII. Lisboa: Imprensa Nacional/Casa da Moeda, 2013.

RODRIGUES, T. F. Para o estudo dos róis de confessados: a freguesia de Santiago em Lisboa (1630-1680). Nova História, Lisboa, n. 3/4, p. 79-106, 1985.

RODRIGUES, M. S. \& NETO, M. S. Informações Paroquiais e História Local. A diocese de Coimbra. Coimbra: Palimage, 2013.

SCHANTZ, A. P. D. Libertos no Rio Grande de São Pedro: Porto Alegre e Viamão no final do século XVIII e início do XIX. 2009. Dissertação (Mestrado em História) - Faculdade de Filosofia e Ciências Humanas, Universidade Federal da Bahia, Salvador.

SCOTT, D. A população do Rio Grande de São Pedro pelos mapas populacionais de 1780 a 1810. Revista Brasileira de Estudos de População, Belo Horizonte, v. 34, n. 3, p. 617-633, 2017.

SEQUEIRA, G. M. Depois do terremoto: subsídios para a história dos bairros ocidentais de Lisboa. Lisboa: Academia das Sciências de Lisboa, 1916.

SILVA, C. L'évêché du Congo et de l'Angola de 1641 à 1760. In: NEIVA, S. (org.). Nouvelles perspectives de la recherche française sur la culture portugaise, 2007. Disponível em: <http://pubp.univ-bpclermont.fr/public/pdf/Nouvellesperspectives.pdf>. Acesso em 9 set. 2020.

SILVA, D. B. D. The Early Population Charts of Portuguese Angola, 1776-1830: A Preliminary Assessment. Anais de História de Além-Mar, Lisboa, v. 16, p. 107-124, 2015.

SILVA, F. R. Counting People and Homes in Urban Mozambique in the 1820s: Population Structures and Household Size and Composition. African Economic History, v. 45, n. 1, p. 4676, 2017.

SILVA, F. R. From church records to royal population charts: The birth of "modern demographic statistics" in Mozambique, 1720s-1820s. In: Anais de História de Além-Mar, n. 16, , p. 17-50, 2015.

SIRTORI, Bruna. Entre a cruz, a espada, a senzala e a aldeia: hierarquias sociais em uma área periférica do Antigo Regime (1765-1784). 2008. Dissertação (Mestrado em História) - Instituto de Filosofia e Ciências Humanas, Universidade Federal do Rio de Janeiro, Rio de Janeiro. 
THOMPSOM, E. C. Taking the Graduate Students to Luanda and Benguela: A Brazilian Perspective. The Harriet Tubman Newsletter, n. 31, p. 14-25, 2012.

THORNTON, J. K. The Slave Trade in Eighteenth century Angola: Effects on Demographic Structures. Canadian Journal of African Studies, v. 14, p. 417-427, 1980.

THORNTON, J. K. A History of West Central Africa to 1850. Cambridge: Cambridge University Press, 2020.

VENÂNCIO, J. C. A economia de Luanda e Hinterland no século XVIII. Lisboa: Estampa, 1996.

WAGNER, A. P. População no Império Português: recenseamentos na África Oriental portuguesa na segunda metade do século XVIII. 2009. Tese (Doutorado em História) - Setor de Ciências Humanas, Letras e Artes, Universidade Federal do Paraná, Curitiba.

WAGNER, A. P. Porque sua Majestade quer saber o "número de vassalos que habitam nos seus domínios": recenseamentos da África Oriental Portuguesa no último quartel do século XVIII". In: XVII Encontro Nacional de Estudos Populacionais, n. 27, 2010, Caxambú: ABEP, 20 a 24 de setembro, p. 1-20.

ZAU, F. Angola: Trilhos Para o Desenvolvimento. Lisboa: Universidade Aberta, 2002. 